\title{
A água em estado crítico
}

\author{
Por Carlos Hiroo Saito, Melissa Curi, Gabriela Litre,
} Marcel Bursztyn

doi:10.18472/SustDeb.v8n3.2017.28096

O ano de 2017 está chegando ao seu final. 2018 já está na porta, trazendo suas marcas, suas expectativas. $\mathrm{E}$ como podemos encarar essa transição? $\mathrm{O}$ que o ano que passa nos deixa como mensagem e o que o novo ano nos conclama à reflexão?

O ano de 2017 foi marcado, em plena Capital Federal do Brasil, pela crise da água, que exigiu da companhia distribuidora a implementação de um racionamento de água por regiões do Distrito Federal em sistema de rodízio. O racionamento repetiu a experiência similar vivida por São Paulo, marcadamente entre 2014 e 2016.

Mas nem sempre o desabastecimento é motivado pela diminuição de água nos reservatórios em decorrência de diminuição das chuvas - um problema de quantidade. O rompimento da barragem de Fundão, em novembro de 2015 (conhecido como a tragédia de Mariana), completou dois anos sem que os problemas socioambientais decorrentes do acidente estejam plenamente sanados, remetendo a um outro aspecto causador de desabastecimento: a questão da qualidade.

Juntos, qualidade e quantidade, asseguradas de forma contínua, tem sido foco da atenção da comunidade internacional na consolidação do conceito de segurança hídrica, garantidor do direito humano à água. Mas é importante lembrar que a definição de segurança hídrica apresentada pela ONU-Água, em 2013, nos remete a um olhar ainda mais amplo que a necessária atenção ao problema do abastecimento humano. Segurança Hídrica, nessa definição, exige que consideremos a proteção dos ecossistemas, tanto para que possam prover de água o abastecimento humano, como também para proteger a biodiversidade que dela depende.

A tragédia de Mariana é exemplar nessa conjunção multifocal do conceito de segurança hídrica: o necessário entrelaçamento entre prevenção de desastres, o abastecimento humano, o desenvolvimento das atividades produtivas e a proteção dos ecossistemas, além de chamar atenção para a necessidade de implementar mecanismos que diminuam a vulnerabilidade geopolítica de entes governamentais e comunidades frente às formas de uso inadequadas da terra à montante.

Essa vulnerabilidade apareceu de forma concreta sobre os municípios afetados à jusante do rio Doce, no estado do Espírito Santo. Curiosamente, o acidente de Mariana ocorreu no ano em que se encerrou a Década Internacional para Ação “Água para a Vida" (2005-2015), proclamada pela ONU na Assembleia Geral/Resolução: A/RES/58/217).

A importância do tema dedicado por essa década e a continuidade das preocupações que motivaram sua decretação levaram a mesma ONU a declarar uma nova década com foco na água: 2018-2028 - Década Internacional para Ação "Água para o Desenvolvimento Sustentável" (Assembleia Geral/ Resolução: A/RES/71/222).

Nesse contexto, o novo ano que já se anuncia vem retomando e reforçando a preocupação internacional com a sustentabilidade da água, que ganha ainda mais ênfase com a realização, em março de 2018 , do 80 Fórum Mundial da Água, organizado pelo Conselho Mundial da Água, na cidade de Brasília. Sua primeira edição aconteceu em 1997, em Marrakesh, no Marrocos, e, desde então, vem se tornando o maior evento sobre esse tema no mundo. 
O Fórum Mundial da Água é um encontro tri-anual que reúne autoridades governamentais, profissionais do setor de ciência e tecnologia, setor privado, usuários e sociedade civil para debater diversos assuntos relacionados à agua. Está estruturado em 5 grandes atividades: processo temático, que tratará dos principais temas a serem abordados pelo Fórum (Clima, Pessoas, Desenvolvimento, Urbano, Ecossistemas e Financiamento, além dos temas transversais Governança, Capacitação e Compartilhamento); processo político, que vai envolver os governantes nos níveis local, regional e nacional, visando a produção de protocolos de entendimento, acordos e tratados de cooperação para a gestão integrada das águas; processo regional, que discutirá os principais problemas e as diretrizes e os mecanismos possíveis para cooperação e gestão integrada das águas nos continentes ou regiões geográficas; Grupo Focal em Sustentabilidade, que se ocupará de tentar identificar as aderências entre políticas públicas e os princípios do desenvolvimento sustentável, participando dos demais processos; e Fórum Cidadão, que buscará promover a participação da sociedade civil organizada nas discussões, trocas de experiências e das demais atividades do Fórum.

No entanto, simultaneamente ao Fórum Mundial da Água, está também em andamento a organização do Fórum Alternativo Mundial da Água (FAMA), na mesma cidade de Brasília. Seus organizadores justificam o chamamento ao evento alternativo sob o argumento de que o Fórum Mundial da Água visaria validar as políticas de privatizações dos governos e, simultaneamente, influenciar a opinião pública e os tomadores de decisão para uma visão e gestão privatista dos recursos hídricos.

Aos críticos do Fórum Mundial da Água, seus organizadores respondem com a sinalização de maior abertura, ressaltando o fato de que o evento é realizado pela primeira vez no hemisfério sul, esperando com isso ampliar a participação dos países periféricos e semiperiféricos da economia mundial. A criação do Fórum Cidadão também responderia pela maior abertura à participação social.

O confronto das duas visões apenas ilustra a importância e atualidade do tema, que inclusive aumenta de importância e expectativas à medida que a data dos dois eventos se aproxima, de 18 a 23 de março de 2018, antes do fechamento da edição seguinte de Sustentabilidade em Debate. É papel desse editorial chamar a atenção para o momento ímpar que vivemos e a importância da água na determinação da sustentabilidade, especialmente pelo fato de a água estar presente, nutrindo e conduzindo vários elementos dos diferentes Objetivos do Desenvolvimento Sustentável (ODS), também em discussão em todo o mundo.

E é nesse contexto que SeD decidiu apresentar, nesse último número de 2017, um dossiê temático sobre Água e Gênero, em sintonia com debates no âmbito internacional sobre a necessidade de valorizar as diferentes visões de mundo e de gestão que possam brotar das diferenças de gênero.

Ao abordar essas dimensões a revista debruça-se sobre um dos pilares da gestão integrada de recursos hídricos, que é a equidade social e o reconhecimento de que a questão do acesso à água é marcada por clivagens de classe, sexo, etnia e geração. Com essa perspectiva, pretende-se promover uma articulação entre as interfaces dos ODS 6 - Água e Saneamento e o ODS 5 - Igualdade de Gênero.

Acredita-se que o respeito e o acolhimento das diferentes visões provenientes de Gênero possam dar riqueza e resiliência à gestão dos recursos hídricos, contribuindo positivamente para a realização do direito humano à água.

O Dossiê, intitulado "Gênero: uma abordagem necessária para a gestão da água", com essa abertura para uma análise ampla sobre o tema, apresenta uma Entrevista com a Ds. Alice M. Bouman-Dentener e quatro artigos científicos, que abordam a questão da Água e Gênero em contextos geográficos e culturais diversificados.

Nesta edição, Sustentabilidade em Debate apresenta também oito artigos em sua seção Varia. Dentro do amplo espectro da sustentabilidade, os trabalhos tratam, em linhas gerais, de meio ambiente, sociedade e desenvolvimento, paradigmas ecológicos, sistemas sociais comunitários e licenciamento ambiental.

O primeiro artigo Varia, intitulado "The state of India's environment: reflecting its Underdevelopment", do autor V. Santhakumar, é um texto de opinião que aborda os principais problemas ambientais da Índia contemporânea. O trabalho faz uma análise sobre a interrelação entre a esfera econômica (subdesenvolvimento) e os resultados ambientais. 
Ainda abordando a temática sobre desenvolvimento e sociedade, o artigo "Tendências e Perspectivas do Novo Paradigma Ecológico: uma revisão sistemática da produção científica", dos autores Edson Talamini et al., apresenta os resultados de uma pesquisa bibliográfica a respeito da produção científica sobre o Novo Paradigma Ecológico (NEP), identificando tendências e perspectivas referentes à sua aplicação.

Os autores Hirdan Katarina de Medeiros Costa, André Felipe Simões e Edmilson Moutinho dos Santos, no artigo "The Integral Sustainability as driving force for paradigmatic change in human lifestyle", também levantam as questões paradigmáticas que envolvem a proposta de desenvolvimento sustentável. Para tanto, recuperam e ampliam a discussão sobre o conceito de sustentabilidade.

No artigo "O sistema terrestre (land system) como plataforma de integração e interpretação das complexas relações ambiente-sociedade", os autores Evandro Albiach Branco, Daniel Rondinelli Roquetti e Evandro Mateus Moretto fazem uma reflexão sobre as relações entre o sistema terrestre, a interdisciplinaridade e a complexidade.

Raul Asseff Castelão et al., no artigo "Empregos verdes na região do Pantanal brasileiro", dentro de um contexto de promoção de atividades que assegurem a preservação ambiental, fazem um levantamento sobre os "empregos verdes" na região do Pantanal, entre os anos de 2002 a 2015.

Com pesquisa em outro bioma, mas também com enfoque socioambiental, os autores Luiz Cláudio Moreira Melo Júnior, Doris Sayago e Manoel Malheiros Tourinho, no artigo "Sistemas sociais comunitários ribeirinhos na Amazônia: dinâmicas socioambientais em questão", abordam a dinâmica socioambiental recente $(2008 / 2014)$ dos sistemas sociais das comunidades ribeirinhas localizadas em uma região de fronteira aberta ao longo do Rio Arapiuns, no oeste do estado do Pará.

Com a mesma perspectiva comunitária, o artigo "Percepção de agricultores familiares e empresariais de Tomé-Açu, Pará, Brasil sobre os Sistemas de Agrofloresta", dos autores Gisele Pompeu, Osvaldo Kato e Ruth Almeida, faz uma análise sobre percepção de sistemas agroflorestais, por meio de abordagens quantitativas e qualitativas.

Por fim, os autores Emanoele Lima Abreu e Alberto Fonseca, no artigo "Análise comparada da descentralização do licenciamento ambiental em municípios dos estados de Minas Gerais e Piauí", fazem uma avaliação comparativa entre experiências de municipalização do licenciamento ambiental em dois municípios no estado do Piauí (Teresina e Água Branca) e dois municípios no estado de Minas Gerais (Belo Horizonte e Betim). A abordagem metodológica foi qualitativa por meio de estudo de casos múltiplos, com dados coletados em análises documentais e entrevistas estruturadas com representantes de prefeituras.

Aproveitando essa força de reflexão e de balanço das atividades que o fim dio ano promove, ressaltamos que, em 2017, SeD intensificou sua proposta de ampliar o seu fator de impacto no âmbito internacional. Para tanto, a revista reforçou as suas chamadas para manuscritos em língua estrangeira e, simultaneamente, ampliou a sua indexação em bases de buscas de periódicos. $O$ último balanço nos permite orgulhosamente informar que Sustentabilidade em Debate está indexada nas seguintes plataformas: Scopus, Crossref, EZB, UlrichsWeb, Latindex, DOAJ, EBSCO.

Para manter e ampliar as possibilidades de indexadores, estamos operando ajustes processuais na revista, tais como a definição clara e transparente das etapas de análise dos manuscritos submetidos, atualização do Conselho Editorial, ampliação do corpo de pareceristas e um suporte maior aos avaliadores para que mantenham uma avaliação qualificada e rigorosa dos artigos. Além do interesse de SeD em se tornar cada vez mais um periódico de referência na temática da sustentabilidade, o esforço da equipe editorial e de seus colaboradores está afinado com os princípios éticos da revista de responsabilidade com o desenvolvimento da ciência.

Boa leitura para todos e feliz 2018.

Os Editores 